\title{
Prevalence of Sexual Problems and Associated Distress in Aging Men Across 4 European Countries
}

\author{
Gert Martin Hald, $\mathrm{PhD},{ }^{1}$ Cynthia Graham, $\mathrm{PhD}^{2}$ Aleksandar Štulhofer, $\mathrm{PhD}^{3}$ Ana Carvalheira, $\mathrm{PhD}^{4}$
}

Erick Janssen, $\mathrm{PhD}^{5}$ and Bente Træen, $\mathrm{PhD}^{6}$

\begin{abstract}
Background: Among older men, comparable cross-cultural investigations of sexual problems and associated distress that also include a multitude of relevant explanatory variables of these sexual problem and related distress are rare in the research literature.
\end{abstract}

Aims: To investigate prevalence rates of sexual problems and associated distress among older men across 4 European countries (Norway, Denmark, Belgium, and Portugal) and assess for associated mental and physical health-related factors.

Methods: Multinational cross-sectional questionnaire study using self-report measures.

Outcomes: Prevalence rates of sexual problems and associated distress levels.

Results: We found a high prevalence of sexual problems persisting for months or longer across countries, but noted that many affected men experienced minimal or no distress related to these problems. We also found marked cross-cultural differences in reported distress about sexual problems, with southern European men (i.e., Portugal) reporting significantly more distress related to the majority of sexual problems investigated compared with northern European men (i.e., Denmark and Norway). Finally, we identified several relational, physical, and mental health problems associated with the reported number of sexual problems and the distress related to these problems.

Clinical Implications: We suggest that healthcare professionals also target distress when considering sexual problems among older men and contextualize these considerations within a multifactorial approach to general health in which (other) mental and physical health factors relevant to these patients' sexual health and function are also jointly considered.

Strengths \& Limitations: Strengths of this study include the large sample size, inclusion of participants from 4 European countries, assessment of distress associated with sexual problems, and similar research design and method of data collection across the 4 included countries. Limitations of the study include the cross-sectional design, which precludes causal conclusions; the low response rate in the Portuguese sample; the lack of homosexual participants; and the lack of comprehensive assessments of dyadic factors that may be of relevance to sexual problems and associated distress.

Conclusion: This study identified a high prevalence of sexual problems persisting for 3 months or longer among older men across 4 European countries, but also found that many of the men with sexual problems experienced minimal or no distress related to these problems. G.M. Hald, C. Graham, A. Stulhofer, et al. Prevalence of Sexual Problems and Associated Distress in Aging Men Across 4 European Countries. J Sex Med 2019;XX:XXX-XXX.

Copyright (C) 2019, International Society for Sexual Medicine. Published by Elsevier Inc. All rights reserved.

Key Words: Sexual Problems; Sexual Functions; Sexual Distress; Cross-Cultural; Older Men

Received October 12, 2018. Accepted April 10, 2019.

'Department of Public Health, University of Copenhagen, Copenhagen, Denmark;

2Department of Psychology, University of Southampton, Southampton, United Kingdom;

${ }^{3}$ Department of Sociology, University of Zagreb, Zagreb, Croatia;
${ }^{4}$ Department of Psychology, University of Lisbon, Lisbon, Portugal;

${ }^{5}$ Department of Psychology, University of Leuven, Leuven, Belgium;

${ }^{6}$ Department of Psychology, University of Oslo, Oslo, Norway

Copyright @ 2019 , International Society for Sexual Medicine. Published by Elsevier Inc. All rights reserved.

https://doi.org/10.1016/j.jsxm.2019.04.017 


\section{INTRODUCTION}

In Western societies, current generations of older adults place a higher value on sexual health and activity than previous ones. ${ }^{1}$ Many older adults consider sexual relationships important ${ }^{2-5}$ and are sexually active well into their 70 s and 80 s. 6,7 Whereas the frequency of sexual intercourse tends to decrease with age, 8,9 sexual activity continues to foster emotional intimacy and contributes to relationship strength in older age. ${ }^{10-12}$ Active and satisfying sexual relationships in older adults have been associated with both quality of life ${ }^{13}$ and physical and psychological wellbeing, 2,3,11,14-16 yet healthy sexual aging remains underprioritized in research and public policy development. , $9,17-20^{8}$ Although there is inconsistency in the literature concerning the definition of an "older adult," most definitions focus on individuals who are at least 60 or 65 years of age. ${ }^{2,3}$

The frequency of sexual behavior tends to decrease over time; however, this often occurs in a nonlinear fashion and is affected by gender. ${ }^{8,21}$ In contrast, the importance of sex, attitudes about the relevance of sexual activity for the relationship, and sexual satisfaction appear to be relatively stable across life stages, ${ }^{3}$ particularly among partnered men and women who are in good physical health. $8,18,22$ In this regard, it has been found that male partners' sexual problems are associated with reduced levels of sexual activity and the importance that both partners attach to sex. ${ }^{14,23}$

More epidemiologic research on sexual problems in older men has been published over the past 2 decades, with the majority of studies focusing on erection problems. ${ }^{24}$ This research shows that sexual problems are more prevalent in older men than in younger men across all domains of sexual function, although prevalence estimates vary widely. ${ }^{21,25-33}$ For men age $65+$ years, estimated prevalences range from $10 \%$ to $77 \%$ for erectile problems, ${ }^{30,34-38}$ from $14 \%$ to $48 \%$ for decreased desire/interest in sex, ${ }^{29,30,36,39}$ from $6 \%$ to $39 \%$ for delayed orgasm, from $11 \%$ to $28 \%$ for early orgasm, and from $2 \%$ to $3 \%$ for pain during intercourse. $^{29,30,34,39}$ The main predictors of sexual problems in men have been identified as be relationship status (ie, lack of a steady partner), ${ }^{30,40}$ poor physical health,,$^{30,41-43}$ and poor mental health. ${ }^{40,43}$

Three important gaps in the literature on sexual problems in aging men can be identified. First, distress associated with sexual problems has been severely understudied. This is problematic, given that distress has been a required diagnostic criterion for diagnosing sexual problems as male sexual dysfunctions in the Diagnostic and Statistical Manual of Mental Disorders (DSM) since $1994 .{ }^{44}$ Men who report sexual problems do not always experience them as distressing and thus might not meet the criteria for a formal diagnosis that "opens the door" to public health services. For example, the British Third National Survey of Sexual Attitudes and Lifestyles (NATSAL-3) found that $42 \%$ of men reported sexual problems, but only $10 \%$ reported feeling distress about these problems, with no difference in distress between sexually active men and inactive men. ${ }^{30}$ Similarly, studies on the pervasiveness of sexual problems in men have found much higher prevalence rates when these rates are based on (mostly physiological) symptoms and not on the co-occurrence of both symptoms and associated distress. ${ }^{45-47}$

The type of sexual problem has been found to moderate experiences of distress, with men experiencing anorgasmia and decreased erectile functioning reporting the most distress. ${ }^{25,47-50}$ Factors found to be associated with less distress related to sexual problems include older age, increased emotional closeness during sex, more frequent intercourse, greater sexual satisfaction, and better sexual functioning. ${ }^{30,49,51-53}$ In contrast, increased relationship duration, conflict with partner regarding sexual issues, and greater severity of the sexual problem have been associated with increased distress. ${ }^{49,52-54}$ However, very few of these studies included substantial cohorts of older men, and none focused explicitly on older men only. Thus, whether the same factors moderate experiences of distress in older men as well remains unclear.

The second gap in the literature concerns the lack of multinational studies, which enables comparisons of sexual problems and associated distress across countries and cultures. To the best of our knowledge, sexual problems and correlates have been previously studied and compared in aging men across national samples, ${ }^{52}$ but associated distress has not. Accordingly, in the present study we focused on possible differences in sexual problems and related distress among older men in 2 northern European countries (Norway and Denmark), a more centrally located European country (Belgium), and a southern European country (Portugal). Compared with northern Europe, in southern Europe there is a much stronger adherence to traditional masculine gender constructs and roles. ${ }^{55,56}$ Given that sociocultural variables, including gender constructs, roles, and stereotypes, may influence perceptions of sexuality and distress related to sexual problems,' these may differ across countries. Using multinational samples using comparable methodology, design, and measures allowed us to explore such possible country-level differences.

The third gap in the literature relates to the relative paucity of research that includes a more comprehensive array of previously indicated correlates and predictors of older mens' sexual problems and distress and assesses their explanatory value in relation to them. ${ }^{5}$

To address these gaps in the literature, we used recently collected data from cohorts of European men age 60-75 years from Norway, Denmark, Belgium, and Portugal to investigate the following research questions:

1. What are the prevalence rates of sexual problems and associated distress in older men in Norway, Denmark, Belgium, and Portugal?

2. Is there a difference in the prevalence rates of sexual problemrelated distress between the 2 northern European countries 
Table 1. Sample characteristics

\begin{tabular}{|c|c|c|c|c|c|c|c|c|}
\hline \multirow[b]{2}{*}{ Characteristic } & \multicolumn{2}{|c|}{ Norway $(\mathrm{N}=590)$} & \multicolumn{2}{|c|}{ Denmark ( $N=442)$} & \multicolumn{2}{|c|}{ Belgium ( $N=256$ ) } & \multicolumn{2}{|c|}{ Portugal (N = 179) } \\
\hline & Mean \% (n) & SD & Mean \% (n) & SD & Mean \% (n) & SD & Mean \% (n) & SD \\
\hline Age & 67.29 (590) & 4.37 & 67.67 (442) & 4.31 & $67.07(256)$ & 4.27 & 65.86 (179) & 4.33 \\
\hline \multicolumn{9}{|l|}{ Educational level } \\
\hline Primary & $9.2(54)$ & & $26.4(116)$ & & $9.4(24)$ & & $23.5(42)$ & \\
\hline Secondary & 32.4 (191) & & 36.1 (159) & & $48.8(125)$ & & $53.6(96)$ & \\
\hline Tertiary & $58.5(345)$ & & $37.5(165)$ & & $41.8(107)$ & & 22.9 (41) & \\
\hline Religiosity, attending services (1-7) & $2.4(582)$ & 1.60 & $2.53(438)$ & 1.66 & $2.73(255)$ & 2.01 & 3.31 (175) & 2.08 \\
\hline \multicolumn{9}{|l|}{ Sexual orientation } \\
\hline Heterosexual & $96.8(570)$ & & 96.5 (418) & & $93.3(235)$ & & 94.0 (158) & \\
\hline \multicolumn{9}{|l|}{ Relationship status } \\
\hline In a relationship & 87.4 (51) & & $87.1(384)$ & & $87.0(221)$ & & 92.7 (165) & \\
\hline \multicolumn{9}{|l|}{ Mental health indicators } \\
\hline Anxiety \& Depression (0-4) & 1.39 (589) & 0.43 & 1.37 (441) & 0.46 & $1.47(254)$ & .54 & $1.48(173)$ & 0.44 \\
\hline SF-12 Mental Health (1-100) & $55.56(526)$ & 6.91 & 55.54 (392) & 6.66 & 54.17 (210) & 6.76 & $54.52(141)$ & 6.62 \\
\hline \multicolumn{9}{|l|}{ Physical health indicators } \\
\hline Health Problems (0-11) & 0.95 (590) & 0.98 & $1.2(442)$ & 1.06 & $1.02(256)$ & 1.03 & 1.12 (179) & 0.9 \\
\hline SF-12 Physical Health (1-100) & $48.37(526)$ & 8.52 & 49.15 (392) & 8.12 & $48.30(210)$ & 8.60 & $47.00(141)$ & 58.51 \\
\hline \multicolumn{9}{|l|}{ Life style } \\
\hline Hours of exercise per wk & 4.16 (584) & 1.48 & 3.99 (439) & 1.62 & $4.92(254)$ & 1.37 & 3.69 (179) & 1.74 \\
\hline Number of cigarettes per wk & 7.39 (579) & 25.86 & 12.01 (437) & 38.09 & 8.24 (251) & 8.24 & 8.69 (178) & 28.03 \\
\hline Number of alcohol units per wk & $7.41(587)$ & 8.67 & 11.58 (441) & 11.94 & $10.7(253)$ & 10.39 & $8.89(178)$ & 9.51 \\
\hline
\end{tabular}

(ie, Norway and Denmark) and the southern European country (ie, Portugal)?

3. What is the explanatory value of relevant sociodemographic factors (age, relationship status, education, religion, and sexual orientation), lifestyle factors (smoking, alcohol consumption, and exercise), and mental and physical health (functional health, well-being, medical conditions, anxiety, and depression) on number of sexual problems and associated distress levels reported?

\section{MATERIALS AND METHODS}

\section{Participants}

Questionnaire data were collected in national probabilitybased samples of men age 60-75 years in Norway, Denmark, Belgium, and Portugal between October 2016 and January 2017. Data collection was coordinated by the marketing research company IPSOS in cooperation with the Department of Psychology at the University of Oslo, Norway. First, recruitment interviews were conducted by telephone, using landline and mobile registers, to obtain a nationally representative sample of the population of men and women age $60-75$ years in each country. Regardless of gender, during the interview, it was emphasized that responses from sexually inactive individuals were equally important as those of sexually active individuals. Only data collected from men were used for this article; findings relating to women will be reported elsewhere. The average age of the men in this study was 67 years in
Norway, Denmark, and Belgium and 66 years in Portugal (SD range 4.27-4.37). Participant characteristics are summarized in Table 1.

\section{Recruitment and Procedure}

The questionnaire was developed in English and subsequently translated into each country's native language by members of the research team and IPSOS's staff in the 4 participating countries. Following this, telephone recruitment of potential participants was initiated. With the exception of Portugal, national phone registries (landline and mobile) were used to produce representative samples of the target population. Because there is no comprehensive national telephone registry in Portugal, the following frequently used procedure for telephone survey recruitment was used there: (i) telephone numbers were first randomly selected from fixed phone directories and IPSOS's own database of phone numbers; (ii) to obtain a distribution representative of the population, men and women were selected by age and gender; and (iii) owing to illiteracy problems, individuals who had not completed primary school (ISCED 1) were excluded from the sample. In all 4 countries, telephone recruitment was carried out between October and December 2016.

Men and women who agreed to participate during the telephone recruitment interview were mailed an anonymous selfadministered questionnaire, including an informed consent form and a Freepost envelope to return the completed questionnaire. Two follow-up reminders were sent at 1 week and 2 weeks after the questionnaire had been mailed. After a discussion 
with IPSOS in Portugal, it was decided to deliver the reminders by phone. Unfortunately, 502 potential Portuguese participants could not be reached. Of the 1,498 Portuguese individuals who were contacted by phone, 561 declined participation after having received the questionnaire. Response rates were 68\% in Norway, $52 \%$ in Denmark, 57\% in Belgium, and 26\% in Portugal. More detailed descriptions of the sample and the procedure are available elsewhere.

\section{Survey Questions}

Sociodemographic variables were taken from the Sweden National Survey of Sexual Behavior 1996, ${ }^{57}$ the British NATSAL- $3,{ }^{30}$ and the Sexual Behavior and Risks of HIV Infection in Europe survey. ${ }^{58}$ Lifestyle factors and mental and physical health indicators were adapted from the NATSAL-3 survey, ${ }^{30}$ the Copenhagen Aging and Midlife Biobank study, ${ }^{59}$ and the Common Mental Disorders Study in Denmark. ${ }^{60}$ Indicators of sexual activity, sexual problems, and associated distress were adapted from NATSAL- $3^{30}$ and the DSM- - . $^{61}$

\section{Measures}

\section{Sociodemographic Variables}

Age was indicated by year of birth. Sexual orientation was assessed by the following question: "Which of the options below best describes how you currently think of yourself? Response options were $1=$ heterosexual, $2=$ gay/lesbian, $3=$ bisexual, and $4=$ other. Responses were later dichotomized into $1=$ heterosexual and $2=$ other.

Relationship status was assessed by asking: "Do you currently have a steady/committed relationship with anybody? A steady/ committed relationship also includes married/cohabiting persons." The response categories were $1=$ yes, $2=$ no, and $3=$ unsure. Nine respondents indicated they were unsure of their relationship status and were included in the "no" category.

Level of education was assessed as the highest level of formal completed education. In Norway, Denmark, and Portugal, the response categories were $1=$ primary school $(6-8$ years of schooling); $2=$ lower secondary school $(9-10$ years of schooling); $3=$ higher secondary school, high school (12-13 years of schooling); $4=$ college, lower university level (bachelor's degree level or similar); and $5=$ higher university level (master's degree, $\mathrm{PhD}$ level, or similar). In Belgium, additional response alternatives were added to mirror the educational system in the country. To allow for cross-cultural comparisons, the variable was subsequently recoded into $1=$ primary $(1), 2=$ secondary ( 2 and 3$)$, and $3=$ tertiary ( 4 and 5 ) education.

The following indicator measured religiosity: "Apart from special occasions such as weddings, funerals, and baptisms, how often do you attend religious services or meetings?" $1=$ once a week or more, $2=$ once every 2 weeks, $3=$ once a month, $4=$ twice a year, $5=$ once a year, $6=$ less than once a year, and $7=$ never.

\section{Sexual Problems and Distress}

Sexual problems were assessed using the following stem "In the last year, have you experienced any of the following for a period of 3 month or longer?" ${ }^{30}$ This was followed by 8 different sexual problems: "lacked interest in having sex," "lacked enjoyment in sex," "felt anxious during sex," "felt physical pain as a result of sex," "felt no excitement or arousal during sex," "did not reach a climax (experienced an orgasm) or took a long time to reach a climax despite feeling excited/aroused," "reached a climax (experienced an orgasm) more quickly than you would have liked," and "had trouble getting or keeping an erection." For each problem, response options were "yes" or "no." A participant who responded "yes" was asked to indicate how much distress the problem had caused him ("no distress," "mild distress," "moderate distress," or "severe distress").

\section{Lifestyle Factors}

Smoking, alcohol consumption and exercise were assessed with the following questions:

Smoking: "On average, how much do you usually smoke during a typical week?" The participant was asked to provide the combined number of cigarettes/cigars/cheroots, etc, and to indicate 000 if he did not smoke.

Exercise: "How many hours per week do you exercise?," with the following explanatory text: "Apart from sports, please also include household and gardening activities, walks, and bike rides to and from work and/or leisure activities."

Alcohol consumption: "On average, how many alcoholic beverages do you consume in a typical week?" Responses were given separately for beer, wine, port/sherry, and spirits and combined into a single score by summing the 4 scores.

\section{Mental and Physical Health and Well-Being Factors}

The Short Form Health Survey 12 (SF-12) was used to measure functional health and well-being from the participant's viewpoint. ${ }^{62}$ The SF-12 includes 12 items and various response scales. Scores were summed using the official coding schemes to provide overall scores on 2 subdimensions: mental health and physical health. Higher scores indicate better health and wellbeing.

Health problems were assessed using the NATSAL-3 questions for medical conditions. ${ }^{63}$ Respondents were asked "has a doctor ever told you that you have any of the medical conditions listed below?," followed by 11 medical conditions (eg, diabetes, prostate cancer, arthritis) (yes/no). Results were summed to provide a score between 0 and 11, with higher scores indicating a greater number of health problems.

Anxiety and depression were assessed using 10 items from the Common Mental Disorders-Screening Questionnaire, ${ }^{60}$ measuring anxiety (4 items) and depression (6 items). Higher scores indicate higher levels of anxiety and depression. Cronbach's $\alpha$ for the scale was 0.85 . 


\section{Statistical Analysis}

SPSS 24.0 (IBM, Armonk, NY, USA) was used to perform $\chi^{2}$ analyses, bivariate analyses, and multiple regression analyses. The proportion of missing data generally was $<5 \%$ across included variables, except for SF-12 data, for which it was $13.5 \%$. Following missing data analyses and assuming data were missing at random, multiple imputation for all descriptive and explanatory variables was conducted using 20 sets of imputations. ${ }^{64}$ For the correlation matrix and multiple regressions, analyses were initially stratified by country, and results were inspected to identify any significant differences among the 4 countries. As neither the magnitude of intercorrelations between variables nor the explanatory value of the relevant included variables in the multiple regression analyses differed considerably across the 4 countries, we report only 1 overall correlation matrix and conducted multiple regression analyses based on the entire sample.

Owing to the item assessing sexual problems and distress specifically targeting "last year," only respondents who had engaged in sexual activity (ie, sexual intercourse, masturbation, petting, or fondling) in the last year were included in the analyses of sexual problems and distress. Only men who reported a sexual problem were asked to respond to questions about their level of distress about that sexual problem. Across the 8 sexual problems, an overall distress score was calculated (summed) based on "no distress" $=0$, "mild distress" $=1$, "moderate distress" $=10$, and "severe distress" $=100$. To maintain maximum power in the regressions, the log-transformed values of the distress scores were used in the analyses, with 1 point added to each overall score.
The assigned distress number (ie, $0,1,10$, or 100) was selected so that higher levels of distress always outranked any combination of preceding levels of distress. For example, any combination of "no" (0) and "mild" distress (1) would always be outranked by 1 or more experiences of "moderate" (10) or "severe" (100) distress. Likewise, any combination of "no" (0), "mild" (1), and "moderate" (10) distress would always be outranked by 1 or more experiences of "severe" (100) distress.

In the regression analysis for number of sexual problems, we used a 1-step entry procedure. For each of the 3 regression analyses for distress, we used a 2-step entry procedure. In the 2-step procedure, in the first step, we entered all variables simultaneously except "number of sexual problems," which was included in the second step. The 2-step procedure was chosen to assess the explanatory effect of the number of sexual problems on distress over and above included sociodemographic factors, life style factors, and mental and physical health-related factors.

\section{RESULTS}

Across the 4 countries, a majority of men $(73.7 \%-79.8 \%)$ had experienced at least 1 sexual problem, and between $49.1 \%$ (Denmark) and 58.2\% (Belgium) had experienced 2 or more sexual problems persisting for 3 months or longer in the last year (Tables 2 and 3). Across the 4 countries, the 3 most prevalent sexual problems were (i) erectile problems, (ii) reaching orgasm more quickly than desired, and (iii) failure to reach orgasm or taking too long to climax. Across countries, physical pain as a

Table 2. Prevalence rates in men who had sexual activity in the last year and experienced sexual problems for 3 months or longer in the last year

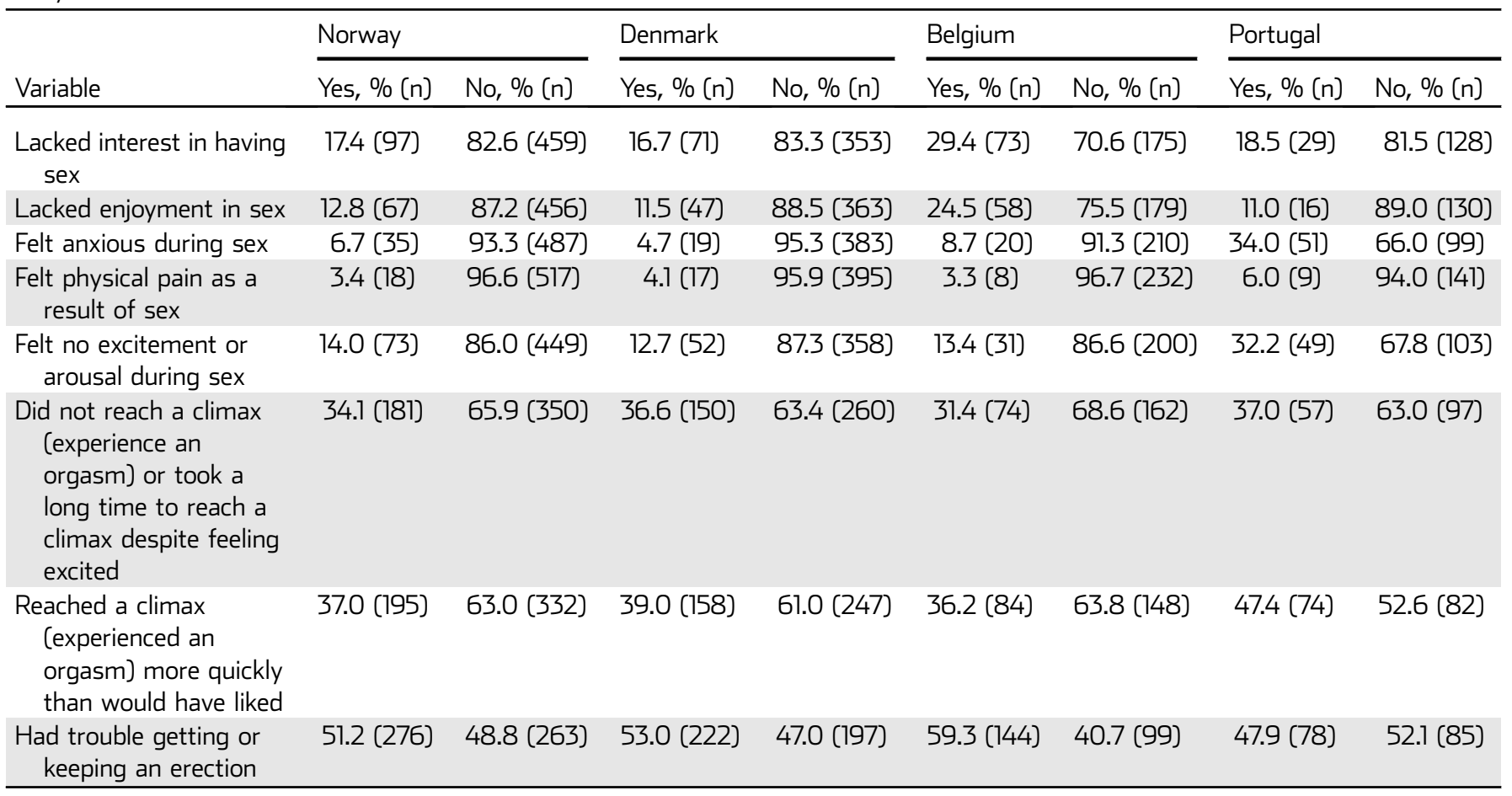

Missing values are excluded. 
Table 3. Accumulated number of sexual problems in men who had sexual activity in the past year and experienced sexual problems for 3 months or longer in the last year

\begin{tabular}{lllll}
\hline & $\begin{array}{l}\text { Norway } \\
(\mathrm{N}=479), \%(\mathrm{n})\end{array}$ & $\begin{array}{l}\text { Denmark } \\
(\mathrm{N}=375), \%(\mathrm{n})\end{array}$ & $\begin{array}{l}\text { Belgium } \\
(\mathrm{N}=208), \%(\mathrm{n})\end{array}$ & $\begin{array}{l}\text { Portugal } \\
(\mathrm{N}=130), \%(\mathrm{n})\end{array}$ \\
\hline $\begin{array}{l}\text { Accumulated number of sexual problems } \\
\text { None }\end{array}$ & $26.3(126)$ & $24.8(93)$ & $20.2(42)$ & $26.2(34)$ \\
1 & $22.1(106)$ & $26.1(98)$ & $21.6(45)$ & $17.7(23)$ \\
2 & $23.6(113)$ & $25.3(95)$ & $25.0(52)$ & $16.2(21)$ \\
3 & $14.8(71)$ & $12.5(47)$ & $17.8(37)$ & $13.8(18)$ \\
4 & $7.7(37)$ & $5.6(21)$ & $8.7(18)$ & $13.1(17)$ \\
5 & $4.6(22)$ & $2.7(10)$ & $4.3(9)$ & $5.4(7)$ \\
6 or more & $0.8(4)$ & $2.9(11)$ & $2.4(5)$ & $7.7(10)$ \\
$\begin{array}{l}\text { Accumulated number of sexual problems } \\
\text { dichotomized }\end{array}$ & & & & $26.2(34)$ \\
$\quad$ None & $26.3(126)$ & $24.8(93)$ & $20.2(42)$ & $73.8(96)$ \\
\hline 1 or more & $73.7(353)$ & $75.2(282)$ & $79.8(166)$ & \\
\hline
\end{tabular}

Missing values are excluded. Range of 0-8 (lacked interest in having sex, lacked enjoyment in sex, felt anxious during sex, felt physical pain as a result of sex, felt no excitement or arousal during sex, did not reach a climax (experienced an orgasm) or took a long time to reach a climax despite feeling excited, reached a climax (experienced an orgasm) more quickly than you would have liked, had trouble getting or keeping an erection).

result of sex was the least often reported problem, with prevalence rates ranging between $3.3 \%$ (Belgium) and $6.0 \%$ (Portugal). Levels of distress related to sexual problems were generally highest for erectile problems. No clear distress pattern for other sexual problems emerged across the 4 countries (Table 4).

Regarding our second research question, we found clear evidence of differences between the 2 northern European countries (Denmark and Norway) and the southern European country (Portugal) in reported distress about sexual problems. For 5 of the 8 sexual problems, older southern European men reported significantly more distress than older northern European men $(P<.05$ and .001 , respectively), whereas the reverse was not evident for any of the sexual problems. Differences in distress level about specific sexual problems were strongest for (i) reaching an orgasm more quickly than desired, (ii) erectile problems, and (iii) failure to reach orgasm or taking too long to climax. In this regard, older Belgium men's distress profile related to sexual problems approximated that of southern European men more closely than that of northern European men.

To investigate our third research question, we conducted 4 separate multivariate regression analyses, including 1 analysis for the overall number of sexual problems and 3 analysis for levels of distress related to specific sexual problems. Following Carvalho et al, ${ }^{65}$ who found that the sexual response of men with sexual difficulties could best be characterized by a "general sexual difficulty factor" and a "premature ejaculation factor," we summed distress scores for (i) sexual problems related to sexual interest, erectile function, and orgasmic function (ie, "general sexual function distress"); (ii) premature ejaculation (ie, "early ejaculation distress"); and (iii) all 8 sexual problems assessed (ie, "overall sexual problems distress"). ${ }^{65}$
For each of the 4 regression analyses, we first inspected pointbiserial correlations (Table 5), because inclusion of a large number of variables in regression models is not recommended unless there are compelling reasons to do so. Consequently, for each regression, we included only variables that were significantly correlated with the criterion variable.

As shown in Table 6, the regression model for number of sexual problems was highly significant, accounting for $9.6 \%$ of the explained variance in sexual problems $(r=0.316$; adjusted $\left.R^{2}=0.096 ; P<.01\right)$. Thus, being in a relationship, lower levels of exercise, a greater number of diagnosed health problems, poorer physical and mental health, and more symptoms of anxiety and depression significantly predicted a higher frequency of sexual problems.

For distress related to sexual problems, all 3 regression models were highly significant $(P<.01)$. For overall sexual problem distress, a greater number of diagnosed health problems, poorer physical health, and a greater number of sexual problems significantly predicted higher levels of overall distress and accounted for $46.5 \%$ of the total explained variance of overall distress $(r=0.683$; adjusted $\left.R^{2}=0.0465 ; P<.01\right)$. For general sexual function distress, a greater number of diagnosed health problems, more symptoms of anxiety and depression, and a greater number of sexual problems significantly predicted increased levels of general function distress and accounted for $42.2 \%$ of the total explained variance of general function distress $\left(r=0.651\right.$; adjusted $R^{2}=$ $0.422 ; P<.01$ ). For early ejaculation distress, poorer mental health, more symptoms of anxiety and depression, and a greater number of sexual problems significantly predicted higher levels of premature ejaculation-related distress and accounted for $8.5 \%$ of the total explained variance of premature ejaculation distress $\left(r=0.297\right.$; adjusted $\left.R^{2}=0.085 ; P<.01\right)$. 
Table 4. Levels of distress among men who have had sexual activity in the past year and experienced sexual problems for 3 months or longer in the last year

\begin{tabular}{|c|c|c|c|c|c|c|c|c|c|c|c|c|c|c|c|c|c|}
\hline \multirow[b]{2}{*}{ Variable } & \multicolumn{4}{|c|}{ Norway level of distress, \% (n) } & \multicolumn{4}{|c|}{ Denmark level of distress, \% (n) } & \multicolumn{4}{|c|}{ Belgium level of distress, \% (n) } & \multicolumn{4}{|c|}{ Portugal level of distress, \% (n) } & \multirow{2}{*}{$\begin{array}{l}\text { North-south } \\
\text { differences }{ }^{\dagger} \\
\text { in level of } \\
\text { distress, } \\
\text { Pearson } \chi^{2} \\
(\mathrm{df}=1)\end{array}$} \\
\hline & None & Mild & Moderate & Severe & None & Mild & Moderate & Severe & None & Mild & Moderate & Severe & None & Mild & Moderate & Severe & \\
\hline $\begin{array}{l}\text { Lacked interest in } \\
\text { having sex }\end{array}$ & $37.5(36)$ & $31.3(38)$ & $26.0(25)$ & $5.2(5)$ & $52.2(35)$ & $31.3(21)$ & $14.9(10)$ & $1.5(1)$ & 19.4 (13) & $32.8(22)$ & $35.8(24)$ & $11.9(8)$ & $9.1(2)$ & $45.5(10)$ & $22.7(5)$ & $22.7(5)$ & $4.001^{*}$ \\
\hline $\begin{array}{l}\text { Lacked enjoyment } \\
\text { in sex }\end{array}$ & 29.2 (19) & $33.8(22)$ & 26.2 (17) & $10.8(7)$ & 40.5 (17) & 40.5 (17) & $16.7(7)$ & 2.4 (1) & $13.2(7)$ & $32.1(17)$ & $47.2(25)$ & $7.5(4)$ & $15.4(2)$ & $23.1(3)$ & $23.1(3)$ & $38.5(5)$ & $5.219^{*}$ \\
\hline $\begin{array}{l}\text { Felt anxious } \\
\text { during sex }\end{array}$ & $8.8(3)$ & $41.2(14)$ & $41.2(14)$ & $8.8(3)$ & $12.5(2)$ & $50.0(8)$ & $31.3(5)$ & $6.3(1)$ & $5.9(1)$ & $35.3(6)$ & $35.3(6)$ & $23.5(4)$ & $13.0(6)$ & $56.5(26)$ & 28.3 (13) & $2.2(1)$ & 2.451 \\
\hline $\begin{array}{l}\text { Felt physical pain } \\
\text { as a result of } \\
\text { sex }\end{array}$ & 5.6 (1) & $55.6(10)$ & 27.8 (5) & $11.1(2)$ & (1) & 78.6 (1ו) & $14.3(2)$ & $0.0(0)$ & $14.3(1)$ & $14.3(1)$ & $57.1(4)$ & $14.3(1)$ & $0.0(0)$ & 44.4 (4) & 44.4 (4) & 11.1 (1) & 2.350 \\
\hline $\begin{array}{l}\text { Felt no excitement } \\
\text { or arousal } \\
\text { during sex }\end{array}$ & $20.3(14)$ & 40.6 (28) & 30.4 (21) & $8.7(6)$ & 58.5 (24) & 26.8 (1ו) & $14.6(6)$ & $0.0(0)$ & $25.9(7)$ & $22.2(6)$ & $37.0(10)$ & $14.8(4)$ & 20.0 (7) & $34.3(12)$ & $22.9(8)$ & 22.9 (8) & 2.931 \\
\hline $\begin{array}{l}\text { Did not reach a } \\
\text { climax } \\
\text { (experience an } \\
\text { orgasm) or } \\
\text { took a long } \\
\text { time to reach a } \\
\text { climax despite } \\
\text { feeling excited }\end{array}$ & 30.6 (53) & $42.2(73)$ & 23.1 (40) & $4.0(7)$ & 43.9 (54) & $34.1(42)$ & $20.3(25)$ & $1.6(2)$ & 13.8 (9) & 36.9 (24) & $30.8(20)$ & $18.5(12)$ & $12.0(6)$ & $44.0(22)$ & $32.0(16)$ & $12.0(6)$ & $7.703^{* *}$ \\
\hline $\begin{array}{l}\text { Reached a climax } \\
\text { (experienced } \\
\text { an orgasm) } \\
\text { more } \\
\text { quickly than } \\
\text { you would } \\
\text { have liked }\end{array}$ & $23.5(42)$ & $49.2(88)$ & $24.6(44)$ & $2.8(5)$ & $54.1(66)$ & 31.1 (38) & 13.1 (16) & $1.6(2)$ & $18.1(13)$ & 34.7 (25) & 31.9 (23) & (ור) 15.3 & 28.6 (18) & $25.4(16)$ & $41.3(26)$ & $4.8(3)$ & $15.162^{* k * k}$ \\
\hline $\begin{array}{l}\text { Had trouble } \\
\text { getting or } \\
\text { keeping an } \\
\text { erection }\end{array}$ & $9.8(25)$ & 34.4 (88) & 43.0 (110) & $12.9(33)$ & 27.0 (51) & 39.7 (75) & $24.3(46)$ & 9.0 (17) & $8.1(10)$ & $29.0(36)$ & $41.9(52)$ & $21.0(26)$ & $7.6(5)$ & $27.3(18)$ & $45.5(30)$ & 19.7 (13) & $8.182^{* k}$ \\
\hline
\end{tabular}

Missing values are excluded.

${ }^{*} P<.05 ;{ }^{* * P}<.01 ;{ }^{* * *} P<.001$

${ }^{\dagger}$ Norway and Denmark vs Portugal. 
Table 5. Correlations among variables of interest

\begin{tabular}{|c|c|c|c|c|c|c|c|c|c|c|c|c|c|c|c|c|c|}
\hline Variable & 1 & 2 & 3 & 4 & 5 & 6 & 7 & 8 & 9 & 10 & 11 & 12 & 13 & 14 & 15 & 16 & 17 \\
\hline $\begin{array}{l}\text { 1. Sexual } \\
\text { problems, } 6 \text { or } \\
\text { highest }\end{array}$ & 1 & & & & & & & & & & & & & & & & \\
\hline $\begin{array}{l}\text { 2. Sexual } \\
\text { problems, none } \\
\text { or } 1 \text { and more }\end{array}$ & $0.67^{* *}$ & 1 & & & & & & & & & & & & & & & \\
\hline $\begin{array}{l}\text { 3. Overall sexual } \\
\text { distress }\end{array}$ & $0.68^{* *}$ & $0.57^{* *}$ & 1 & & & & & & & & & & & & & & \\
\hline $\begin{array}{l}\text { 4. General sexual } \\
\text { function }\end{array}$ & $0.65^{* *}$ & $0.46^{* *}$ & $0.93^{* *}$ & 1 & & & & & & & & & & & & & \\
\hline $\begin{array}{l}\text { 5. Premature } \\
\text { ejaculation }\end{array}$ & $0.30^{* *}$ & $0.23^{* *}$ & $0.48^{* *}$ & $0.26^{\text {*k }}$ & 1 & & & & & & & & & & & & \\
\hline 6. Age & -0.00 & 0.03 & 0.00 & 0.03 & -0.03 & 1 & & & & & & & & & & & \\
\hline $\begin{array}{l}\text { 7. Relationship } \\
\text { status }\end{array}$ & $0.05^{*}$ & $0.06^{*}$ & 0.04 & 0.03 & 0.02 & 0.05 & 1 & & & & & & & & & & \\
\hline $\begin{array}{l}\text { 8. Level of } \\
\text { education }\end{array}$ & -0.01 & 0.01 & 0.02 & 0.02 & -0.00 & -0.03 & -0.00 & 1 & & & & & & & & & \\
\hline 9. Orientation & 0.01 & -0.01 & 0.00 & 0.01 & 0.02 & 0.03 & $-0.14^{* *}$ & $-0.07^{*}$ & 1 & & & & & & & & \\
\hline $\begin{array}{l}\text { 10. Religiosity, } \\
\text { attending } \\
\text { services }\end{array}$ & 0.00 & 0.02 & -0.01 & 0.00 & -0.04 & $0.11^{* *}$ & 0.04 & 0.02 & 0.01 & 1 & & & & & & & \\
\hline $\begin{array}{l}\text { 11. Number of } \\
\text { hours exercise } \\
\text { per week }\end{array}$ & $-0.17^{* *}$ & $-0.07^{\text {*k }}$ & $-0.07^{* * *}$ & $-0.08^{* *}$ & -0.00 & $0.08^{* *}$ & 0.04 & $0.12^{* *}$ & -0.02 & 0.03 & 1 & & & & & & \\
\hline $\begin{array}{l}\text { 12. Number of } \\
\text { cigarettes per } \\
\text { week }\end{array}$ & 0.03 & -0.00 & 0.03 & 0.02 & 0.00 & -0.05 & $-0.08^{* *}$ & -0.04 & $0.07^{* *}$ & $-0.10^{* *}$ & $-0.10^{* *}$ & 1 & & & & & \\
\hline $\begin{array}{l}\text { 13. Units of alcohol } \\
\text { per week }\end{array}$ & 0.02 & $0.05^{*}$ & 0.00 & 0.01 & -0.02 & 0.01 & 0.01 & 0.03 & -0.03 & $-0.15^{* *}$ & 0.02 & $0.13^{* *}$ & 1 & & & & \\
\hline $\begin{array}{l}\text { 14. Health } \\
\text { problems }\end{array}$ & $0.13^{* *}$ & $0.09 * *$ & $0.16^{* *}$ & $0.17^{* * *}$ & 0.04 & $0.16^{* * *}$ & $-0.05^{*}$ & $-0.08^{* *}$ & 0.02 & 0.04 & $-0.10^{* *}$ & -0.03 & -0.01 & 1 & & & \\
\hline $\begin{array}{l}\text { 15. SF-12 Physical } \\
\text { Health }\end{array}$ & $-0.17^{* k}$ & $-0.10^{*}$ & $-0.19^{* *}$ & $-0.19^{* *}$ & -0.05 & -0.01 & $0.07^{* *}$ & $0.15^{* *}$ & -0.02 & 0.01 & $0.18^{* *}$ & $-0.06^{*}$ & -0.01 & $-0.28^{* *}$ & 1 & & \\
\hline $\begin{array}{l}\text { 16. SF-12 Mental } \\
\text { Health }\end{array}$ & $-0.20^{\text {*k }}$ & $-0.14^{*}$ & $-0.20^{* *}$ & $-0.19^{* * *}$ & $-0.13^{* *}$ & $-0.07^{* *}$ & $0.07^{* *}$ & 0.03 & -0.02 & 0.01 & $0.17^{* *}$ & $-0.06^{*}$ & $-0.08^{*}$ & $-0.10^{* *}$ & $-0.13^{* *}$ & 1 & \\
\hline $\begin{array}{l}\text { 17. Anxiety \& } \\
\text { Depression } \\
\text { Index }\end{array}$ & $0.23^{* *}$ & $0.14^{* *}$ & $0.24^{* *}$ & $0.23^{* *}$ & $0.10^{* *}$ & $-0.08^{* *}$ & $-0.20^{* *}$ & -0.04 & $0.07^{* *}$ & -0.01 & $-0.09^{* *}$ & $0.10^{* * *}$ & $0.09^{* * *}$ & $0.10^{* *}$ & $-0.24^{* *}$ & $-0.57^{* *}$ & 1 \\
\hline
\end{tabular}


Table 6. Model summary of hierarchical multiple regression analyses predicting sexual problems and related distress

\begin{tabular}{|c|c|c|c|c|c|c|}
\hline \multirow[b]{2}{*}{ Variable } & \multicolumn{3}{|l|}{ Model 1} & \multicolumn{3}{|l|}{ Model 2} \\
\hline & $B$ & SE B & $\beta$ & $B$ & SE B & $\beta$ \\
\hline \multicolumn{7}{|l|}{ Number of sexual problems } \\
\hline Relationship status & 0.515 & 0.120 & $0.110^{* * *}$ & - & - & - \\
\hline Hours of exercise per week & -0.064 & 0.025 & $-0.064^{*}$ & - & - & - \\
\hline Number of diagnosed health problems & 0.119 & 0.040 & $0.077^{*}$ & - & - & - \\
\hline SF-12 Physical Health & -0.017 & 0.005 & $-0.094^{*}$ & - & - & - \\
\hline SF-12 Mental Health & -0.020 & 0.008 & $-0.090^{*}$ & - & - & - \\
\hline Anxiety \& Depression Index & 0.574 & 0.109 & $0.173^{* *}$ & - & - & - \\
\hline $\mathrm{r}$ & & 0.316 & & & & \\
\hline Adjusted $R^{2}$ & & 0.096 & & & - & \\
\hline $\mathrm{F}$ & & $26.579^{* * *}$ & & & - & \\
\hline \multicolumn{7}{|l|}{ Overall sexual problems distress } \\
\hline Hours of exercise per week & -0.010 & 0.026 & -0.011 & 0.026 & 0.020 & 0.023 \\
\hline Number of diagnosed health problems & 0.152 & 0.042 & $0.100^{* *}$ & 0.083 & 0.032 & $0.053^{*}$ \\
\hline SF-12 Physical Health & -0.021 & 0.006 & $-0.114^{* *}$ & -0.010 & 0.004 & $-0.057^{*}$ \\
\hline SF-12 Mental Health & -0.020 & 0.008 & $0.073^{*}$ & -0.007 & 0.007 & -0.019 \\
\hline Anxiety \& Depression Index & 0.476 & 0.120 & $0.148^{* *}$ & 0.165 & 0.093 & 0.053 \\
\hline Number of sexual problems & & & & 0.653 & 0.020 & $0.643^{* *}$ \\
\hline$r$ & & 0.297 & & & 0.683 & \\
\hline Adjusted $R^{2}$ & & 0.085 & & & 0.465 & \\
\hline$\Delta R^{2}$ change & & 0.088 & & & 0.379 & \\
\hline $\mathrm{F}$ for $\Delta R^{2}$ & & $28.27^{* *}$ & & & $1,036.22^{* *}$ & \\
\hline \multicolumn{7}{|l|}{ General sexual function distress } \\
\hline Hours of exercise per week & -0.019 & 0.024 & -0.022 & 0.012 & 0.019 & -0.009 \\
\hline Number of diagnosed health problems & 0.165 & 0.038 & $0.115^{* k}$ & 0.105 & 0.030 & $0.078^{* *}$ \\
\hline SF-12 Physical Health & -0.018 & 0.005 & $-0.112^{* *}$ & -0.008 & 0.004 & -0.034 \\
\hline SF-12 Mental Health & -0.014 & 0.008 & 0.059 & -0.003 & 0.006 & -0.010 \\
\hline Anxiety \& Depression Index & 0.446 & 0.109 & $0.147^{* *}$ & 0.177 & 0.088 & $0.062^{*}$ \\
\hline Number of sexual problems & & & & 0.563 & 0.019 & $0.606^{* *}$ \\
\hline$r$ & & 0.296 & & & 0.651 & \\
\hline Adjusted $R^{2}$ & & 0.081 & & & 0.422 & \\
\hline$\Delta R^{2}$ change & & 0.088 & & & 0.337 & \\
\hline $\mathrm{F}$ for $\Delta R^{2}$ & & $28.07^{* *}$ & & & $854.06^{* *}$ & \\
\hline \multicolumn{7}{|l|}{ Early ejaculation distress } \\
\hline SF-12 Mental Health & -0.012 & 0.005 & $-0.095^{* *}$ & -0.009 & 0.004 & $-0.073^{*}$ \\
\hline Anxiety \& Depression Index & 0.059 & 0.065 & 0.037 & -0.034 & 0.062 & -0.017 \\
\hline Number of sexual problems & & & & 0.157 & 0.014 & $0.295^{* *}$ \\
\hline$r$ & & 0.126 & & & 0.312 & \\
\hline Adjusted $R^{2}$ & & 0.014 & & & 0.096 & \\
\hline$\Delta R^{2}$ change & & 0.016 & & & 0.082 & \\
\hline $\mathrm{F}$ for $\Delta R^{2}$ & & $11.78^{* *}$ & & & $132.23^{* *}$ & \\
\hline
\end{tabular}

${ }^{*} P<.01 ; * * P<.001$

\section{DISCUSSION}

In this cross-country study of European older men, we found a high prevalence of sexual problems persisting for 3 months or longer across countries, but, consistent with previous research, ${ }^{30,52,66}$ many men with sexual problems reported feeling minimal or no distress about these problems. The high rate of reported sexual problems could be related to a selection bias whereby men with sexual problems were more inclined than men without sexual problems to answer the postal survey. Regarding across-country differences, there were marked differences in reported distress level about sexual problems, with southern European men (ie, Portugal) reporting significantly more distress related to 5 of the 8 sexual problems compared with northern European men (ie, Denmark and Norway). In this regard, the sexual distress profile of Belgium men more closely approximated that of southern European men compared with that of northern 
European men. Finally, we identified several relational, physical, and mental health problems associated with the number of sexual problems reported and the distress level related to these problems.

\section{Comparison of Prevalence Rates with Previous Surveys}

Comparing prevalence estimates from different studies is difficult owing to the diverse criteria/definitions of sexual problems, differences in the time frame for the presence of sexual problems, and the different age ranges of samples across studies. ${ }^{52,66}$ However, because we used the same sexual problem questions and time frame as in the British population-based NATSAL-3 survey (and the age range sampled was similar: 60-75 years in our survey vs 65-74 years in NATSAL-3), we can compare the prevalence rates for sexual problems across the 4 countries with the British NATSAL-3 sample. In the present study, across the 4 countries, between $73.7 \%$ and $79.8 \%$ of men reported experiencing 1 or more sexual problems and between $49.1 \%$ and $58.2 \%$ reported 2 or more sexual problems. These percentages are substantially higher than see in NATSAL-3, in which $53.5 \%$ of men age $60-74$ reported 1 or more sexual problems and $13.0 \%$ reported 2 or more sexual problems. ${ }^{30}$ In both surveys, the most common sexual problem reported was trouble getting or keeping an erection, but here again our prevalence rate was considerably higher than that in NATSAL-3 $(47.9 \%-59.3 \%$ vs $30.0 \%)$. Possible reasons for these discrepant rates include the fact that although the questions were identical, NATSAL-3 participants were interviewed with a combination of computer-assisted face-to-face and self-completed questionnaires, whereas our respondents completed anonymous postal questionnaires. It is possible that men might feel more open about disclosing sexual difficulties in an anonymous survey than during an interview.

Other surveys have reported prevalence rates for sexual problems in older men closer to those found in the present study. ${ }^{34,66,67}$ Regarding erection problems specifically, in the US National Social Life, Health, and Aging Project, the prevalence of erection problems for men age $75-85$ years was $43.5 \% .^{29}$ In another national probability sample of US men age $57-85$ years, erection problems occurring "for several months or more" during the past year were reported by $44.6 \%$ of men age $65-74$ years and by $43.5 \%$ of men age $75-85$ years. ${ }^{21}$ In Træen and Stigum' $^{32}$ population-based study in Norway, $34 \%$ of men age 60-67 years reported erection problems. Together with our findings, these studies indicate that sexual problems are frequent in populations of older men across diverse cultures. ${ }^{52}$

\section{Distress About Sexual Problems}

Levels of distress were highest in relation to erection problems, although even for this problem, for 3 of the 4 countries (Norway, Belgium, and Portugal) between $35 \%$ and $44 \%$ of men who selfreported having difficulty reaching or maintaining an erection reported "no" or "mild" distress related to this problem. For Denmark, this percentage was substantially higher $(67 \%)$ and closer to that of the NATSAL-3 sample, in which $67.1 \%$ of men age 65-74 who self-reported erection problems stated they were "not at all" or only "a little" distressed about these problems. As mentioned above, for 5 of the 8 sexual problems evaluated (lacked interest in having sex, lacked enjoyment in sex, difficulty in reaching a climax, reached climax more quickly than would have liked, and trouble getting or keeping an erection), older men in the southern European country (Portugal) reported greater distress than those in northern European countries (Denmark and Norway). In this regard, older Belgian men's distress profile related to sexual problems more closely approximated that of older southern European men.

These data point to at least 2 important findings. First, across European cultures, it appears that a substantial proportion of men report sexual problems but do not experience any or only mild distress related to these problems. This mirrors findings in older women, in whom the probability of experiencing significant levels of distress in relation to sexual problems is inversely related to age; that is, the older the age, the lower the likelihood of experiencing distress. ${ }^{2,8}$ Second, cultural differences in the proportion of men who report sexual problems but do not experience any or mild distress is evident across Europe. As mentioned in the Introduction, this may be a reflection of crosscultural differences in gender constructions, roles, values, and stereotypes that may influence perceptions of sexuality and distress related to sexual problems. ${ }^{9,55,56}$ However, it also may be an effect of a sample selection bias, in that the response rate for the southern European country (Portugal) was low and substantially lower than that for the other included countries (Norway, Denmark, and Belgium). Finally, it also may be that older men simply expect sexual difficulties to appear as a natural and inevitable part of the aging process and thus considered them natural. This perception may influence the affective response associated with the experiences of sexual problems and cause less distress. $^{51,53}$ More research specifically designed to further qualify these findings is needed.

\section{Factors Associated with the Experience of Sexual Problems and Associated Distress}

To date, relatively few studies have investigated factors associated with sexual problems in older men, ${ }^{29,39,52,66}$ and those that have done so focused mainly on physical risk factors for erection problems. ${ }^{34}$ We assessed the associations between a broad range of factors, including lifestyle, relational, physical and mental health factors, and reported sexual problems. Being in a relationship, lower levels of exercise, greater number of diagnosed health problems, poorer general physical and mental health, and more symptoms of anxiety and depression were all associated with a higher frequency of sexual problems.

Our findings are broadly consistent with previous research. Numerous studies have found strong relationships between 
depression and sexual difficulties. ${ }^{7,34}$ There is also consistent evidence indicating that physical health and mental health problems generally are associated with sexual problems. ${ }^{52}$ Among American men and women age 57-85 years, lower satisfaction with intimate relationships, more male sexual problems, and poorer physical and mental health have been linked with sexual health problems. ${ }^{29}$ In a population-based study of Australian men age 75-95 years, risk factors associated with sexual problems included chronic disease, depression, and insomnia. ${ }^{39}$ In the NATSAL-3 survey, across all age groups of men, poorer physical health, limiting disabilities, functional impairment, and depressive symptoms were associated with erectile difficulties. ${ }^{30}$

We also investigated possible associations between sociodemographic, lifestyle, and health variables and distress levels about sexual problems. To the best of our knowledge, no previous studies have explored this in older men. For "overall sexual problem distress," a greater number of diagnosed health problems, poorer physical health, and a greater number of sexual problems were all associated with higher levels of distress. For "general sexual problem distress" (our composite variable of distress related to sexual interest, erectile function, and orgasmic function problems), a greater number of diagnosed health problems, more symptoms of depression and anxiety, and a greater number of sexual problems were all associated with greater levels of general sexual function distress, Predictors for "early ejaculatory distress" were poorer mental health and a greater number of sexual problems.

\section{Clinical and Research Implications}

Although erection problems, reaching orgasm more quickly than desired, and trouble reaching orgasm were the most common sexual problems reported, a sizeable proportion of older men reported lacking enjoyment in sex or feeling anxious during sex. These findings underline the need for researchers to consider men's experience of sexual problems beyond biomedical or "sexual function" difficulties, which have been the focus of most studies carried out in older men.

Our findings also highlight the importance of assessing sexual problems and associated distress in older men, both in epidemiologic surveys and in clinical settings. On the one hand, clinicians should not assume that all older men will be concerned about sexual difficulties, including erection problems. Despite the focus on penetrative sex in many studies, ${ }^{68}$ there is evidence that with increasing age, men and women may place greater importance on other types of sexual activity ${ }^{69}$ and on intimacy with partners. ${ }^{70}$ On the other hand, a substantial proportion of older men are distressed about sexual difficulties. Based on our data, the sexual difficulties most commonly associated with moderate/severe distress across the 4 countries were erection problems, feeling anxious during sex, and lacking enjoyment in sex. Future studies should ascertain the proportion of older adults with moderate/severe distress about their sex life who want to obtain help for these problems. Previous research has found that many older adults do not seek help for sexual difficulties. ${ }^{30,71}$ This may be because older adults are not bothered by their sexual difficulties to a sufficient degree to cause them to seek treatment. However, it may also be related to the fact that health professionals often do not ask older adults about sexual problems and have difficulty detecting sexual problems in their patients, or that older men find it embassing to discuss their sexual difficulties with health care professionals. ${ }^{72,73}$ Therefore, we suggest that healthcare professionals also target distress when considering sexual problems among older men and contextualize these considerations within a multifactorial approach to general health where (other) mental and physical health factors relevant to the patient's sexual health and function are also jointly considered. Furthermore, we suggest that epidemiologic surveys involving older age men more frequently assess sexual problems and related distress and their relationship(s) with more general mental and physical health care outcomes.

\section{Study Strengths and Limitations}

Strengths of this study include the large sample size, inclusion of participants from 4 European countries, assessment of distress associated with sexual problems, use of mainly validated measures that have been used in previous surveys, and similar research design and method of data collection across the 4 countries to enable across-country comparisons.

Some limitations of the study also should be acknowledged. The cross-sectional design precludes us from drawing conclusions about causal relationships. Moreover, the response rate in the Portuguese sample was low, hindering generalization of our results. Taking into account that our analyses only included men who had been sexually active in the past year, our findings may have underestimated the prevalence of sexual problems, especially since these men may be healthier than the general background population in the included countries. Considering that $>95 \%$ of our participants identified as heterosexual, we were unable to include any analysis of sexual orientation as a variable affecting prevalence of, or distress about, sexual problems. Recent qualitative work suggests that sexual difficulties of gay and bisexual men may need to be conceptualized differently than those of heterosexual men ${ }^{74}$; thus, our findings should not be generalized to older men who identify as other than heterosexual. Finally, we assessed a range of sociodemographic, lifestyle, and health factors as possible correlates of sexual problems, but acknowledge that other social and psychological factors also play an important role in the genesis and maintenance of sexual problems. ${ }^{75}$ For example, future research would benefit from considering dyadic and partner-related factors when investigating sexual problems and related distress among older men.

\section{CONCLUSION}

Our present findings add to the growing literature on sexual problems among older populations. The cross-country 
differences in prevalence rates, particularly in the frequency of distress about sexual problems, underscore the importance of the social-cultural context of sexual difficulties and related distress assessment. Furthermore, it should be noted that although high prevalence rates of sexual problems were found across the 4 countries, a sizeable proportion of older men reported only mild or no distress about these problems.

Corresponding Author: Gert Martin Hald, PhD, University of Copenhagen, Øster Farimagsgade 5A, Building 5.1.01, Copenhagen K 1153, Denmark; Tel: +45 28731317 (direct); E-mail: gertmartinhald@gmail.com

Conflicts of interest: The authors report no conflicts of interest.

Funding: This study was funded by Norwegian Research Counsel Grant 250637. G.M.H. was supported by the Carlsberg Foundation Distinguished Associate Professor Fellowship CF-160094.

\section{STATEMENT OF AUTHORSHIP}

\section{Category 1}

(a) Conception and Design Gert Martin Hald; Cynthia Graham; Aleksandar Štulhofer: d

(b) Acquisition of Data Gert Martin Hald; Cynthia Graham; Aleksandar Štulhofer; Ana Carvalheria, Erick Janssen, Bente Træen

(c) Analysis and Interpretation of Data Gert Martin Hald; Aleksandar Štulhofer

\section{Category 2}

(a) Drafting the Article Gert Martin Hald

(b) Revising It for Intellectual Content Gert Martin Hald; Cynthia Graham; Aleksandar Štulhofer; Ana Carvalheria, Erick Janssen, Bente Træen

\section{Category 3}

(a) Final Approval of the Completed Article Gert Martin Hald; Cynthia Graham; Aleksandar Štulhofer; Ana Carvalheria, Erick Janssen, Bente Træen

\section{REFERENCES}

1. Schmidt G, Matthiesen S. Spätmoderne 60-Jährige. In: FORUM, ed. Alter und sexualität. Frankfurt, Germany: BzgA FORUM; 2003. p. 16-24 [in German].

2. Træen B, Hald GM, Graham C, et al. An overview of the literature on sexuality in older adults $(65+)$, part 1 : Sexual function and its difficulties. Int J Sex Health 2016;29:1-10.

3. Træen $B$, Carvalheira AA, Kvalem IL, et al. An overview of the literature on sexuality in older adults $(65+)$, part 2: Body image and sexual satisfaction. Int J Sex Health 2016;29:11-21.

4. Syme M. The evolving concept of older adult sexual behavior and its benefits. Generations 2014;38:35-41.

5. Foley S. Biopsychosocial assessment and treatment of sexual problems in older age. Curr Sex Health Rep 2015;7:80-88.
6. Chao J, Lin Y, Ma M, et al. Relationship among sexual desire, sexual satisfaction, and quality of life in middle-aged and older adults. J Sex Marital Ther 2011;37:386-403.

7. Wang V, Depp C, Ceglowski J, et al. Sexual health and function in later life: A population-based study of 606 older adults with a partner. Am J Geriatr Psychiatry 2015;23:227-233.

8. DeLamater J. Sexual expression in later life: A review and synthesis. J Sex Res 2012;49:125-141.

9. Træen B, Štulhofer A, Janssen E, et al. Sexual activity and sexual satisfaction among older adults in four European countries. Arch Sex Behav 2019;48:815-829.

10. Graugaard C, Pedersen BK, Frisch M. Seksualitet og sundhed. Copenhagen, Denmark: Vidensråd for Forebyggelse; 2012 [in Danish].

11. Laumann EO, Paik A, Glasser DB, et al. A cross-national study of subjective sexual well-being among older women and men: Findings from the global study of sexual attitudes and behaviors. Arch Sex Behav 2006;35:143-159.

12. Træen B, Schaller S. Subjective sexual well-being in a web sample of heterosexual Norwegians. Int J Sex Health 2010; 22:180-194.

13. Flynn T, Gow A. Examining associations between sexual behaviours and quality of life in older adults. Age Ageing 2015; 44:823-828.

14. Fileborn B, Thorpe R, Hawkes G, et al. Sex, desire and pleasure: Considering the experiences of older Australian women. Sex Relation Ther 2014;30:1-14.

15. Müller B, Nienaber C, Reis $\mathrm{O}$, et al. Sexuality and affection among elderly German men and women in long-term relationships: Results of a prospective population-based study. PLoS One 2014;9:e111404.

16. Kleinstäuber M. Factors associated with sexual health and well being in older adulthood. Curr Opin Psychiatry 2017; 30:358-368.

17. Gott M, Hinchliff S. How important is sex in later life? The views of older people. Soc Sci Med 2003;56:1617-1628.

18. Dominguez $L J$, Barbagallo M. Ageing and sexuality. Eur Geriatr Med 2016;7:512-518.

19. Kalra G, Subramanyam A, Pinto C. Sexuality: Desire, activity and intimacy in the elderly. Indian J Psychiatry 2011;53:300306.

20. Lochlainn MN, Kenny RA. Sexual activity and aging. J Am Med Dir Assoc 2013;14:565-572.

21. Lindau $S$, Schumm $L$, Laumann $E$, et al. A study of sexuality and health among older adults in the United States. N Engl J Med 2007;357:762-774.

22. Koskimäki J, Hakama M, Huhtala $H$, et al. Effect of erectile dysfunction on frequency of intercourse: A population based prevalence study in Finland. J Urol 2000;164:367-370.

23. Kontula O, Haavio-Mannila E. The impact of aging on human sexual activity and sexual desire. J Sex Res 2009;46:46-56.

24. Hald GM, Pind M, Borre M, et al. Nordic prostate cancer patients' sexual problems and satisfaction with their sex life following anti-cancer treatment. J Sex Med 2018;6:210-216. 
25. Carvalheira A, Santana R. Individual and relationship factors associated with the self-identified inability to experience orgasm in a community sample of heterosexual men from three European countries. J Sex Marital Ther 2016; 42:257-266.

26. Dunn K, Croft P, Hackett G. Sexual problems: A study of the prevalence and need for health care in the general population. Family Practice 1998;15:519-524.

27. Fugl-Meyer AR, Fugl-Meyer K. Sexual disabilities, problems, and satisfaction in 18-74-year-old Swedes. Scand J Sexol 1999;2:79-105.

28. Laumann EO, Gagnon JH, Michael RT, et al. The social organization of sexuality: Sexual practices in the United States. Chicago, IL: University of Chicago Press; 1994.

29. Laumann E, Waite L. Sexual dysfunction among older adults: Prevalence and risk factors from a nationally representative $U$. S. probability sample of men and women $57-85$ years of age. J Sex Med 2008;5:2300-2311.

30. Mitchell K, Mercer C, Ploubidis G, et al. Sexual function in Britain: Findings from the third national survey of sexual attitudes and lifestyles (NATSAL-3). Lancet 2013; 382:1817-1829.

31. Richters J, Grulich A, Visser R, et al. Sex in Australia: Sexual difficulties in a representative sample of adults. Aust N Z J Public Health 2003;27:164-170.

32. Træen B, Stigum H. Sexual problems in 18-67-year-old Norwegians. Scand J Public Health 2010;38:445-456.

33. Ventegodt S. Sex and the quality of life in Denmark. Arch Sex Behav 1998;27:295-307.

34. Corona G, Lee DM, Forti G, et al. Age-related changes in general and sexual health in middle-aged and older men: Results from the European male ageing study (EMAS). J Sex Med 2010;7:1362-1380.

35. Eardley I, Dean J, Barnes T, et al. The sexual habits of British men and women over 40 years old. BJU Int 2004; 93:563-567.

36. Panser $L A$, Rhodes T, Girman $C J$, et al. Sexual function of men ages 40 to 79 years: The Olmsted County Study of urinary symptoms and health status among men. J Am Geriatr Soc 1995;43:1107-1111.

37. Shiri R, Koskimäki J, Hakama M, et al. Prevalence and severity of erectile dysfunction in 50- to 75-year-old Finnish men. J Urol 2003;170:2342-2344.

38. Wei M, Macera CA, Davis DR, et al. Total cholesterol and high density lipoprotein cholesterol as important predictors of erectile dysfunction. Am J Epidemiol 1994;140:930-937.

39. Hyde Z, Flicker L, Hankey G, et al. Prevalence and predictors of sexual problems in men aged 75-95 years: A populationbased study. J Sex Med 2012;9:442-453.

40. Oyekanmi A, Adelufosi A, Abayomi O, et al. Demographic and clinical correlates of sexual dysfunction among Nigerian male outpatients on conventional antipsychotic medications. BMC Res Notes 2012;5:267.

41. McCabe M, Connaughton C. Psychosocial factors associated with male sexual difficulties. J Sex Res 2014;51:31-42.
42. Štulhofer A, Bajić Z. Prevalence of erectile and ejaculatory difficulties among men in Croatia. Croat Med J 2006;47:114124.

43. Schlichthorst M, Sanci L, Hocking J. Health and lifestyle factors associated with sexual difficulties in men: Results from a study of Australian men aged 18 to 55 years. BMC Public Health 2016;16(Suppl 3):71-80.

44. American Psychiatric Association. In: Diagnostic and statistical manual of mental disorders (DSM-IV). 4th edition. Washington, DC: American Psychiatric Association; 1994.

45. O'Sullivan $L$, Byers $E$, Brotto $L$, et al. A longitudinal study of problems in sexual functioning and related sexual distress among middle to late adolescents. J Adolesc Health 2016; 59:318-324

46. Hendrickx L, Gijs L, Enzlin P. Prevalence rates of sexual difficulties and associated distress in heterosexual men and women: Results from an internet survey in Flanders. J Sex Res 2014;51:1-12.

47. Peixoto M, Nobre P. Prevalence of sexual problems and associated distress among gay and heterosexual men. Sex Relation Ther 2014;30:211-225.

48. Ivanković I, Šević S, Štulhofer A. Distressing sexual difficulties in heterosexual and non-heterosexual Croatian men: Assessing the role of minority stress. J Sex Res 2014;52:647-658.

49. Træen B, Martinussen M, Öberg K, et al. Reduced sexual desire in a random sample of Norwegian couples. Sex Relation Ther 2007;22:303-322.

50. Ventus D, Gunst A, Kärnä A, et al. No evidence for long-term causal associations between symptoms of premature ejaculation and symptoms of anxiety, depression, and sexual distress in a large, population-based longitudinal sample. J Sex Res 2017;54:264-272.

51. Hendrickx L, Gijs L, Enzlin P. Sexual difficulties and associated sexual distress in Flanders (Belgium): A representative population-based survey study. J Sex Med 2016;13:650-668.

52. Rosen R, Heiman C, Long J, et al. Men with sexual problems and their partners: Findings from the International Survey of Relationships. Arch Sex Behav 2016;45:159-173.

53. Rowland DL, Kolba TN. The burden of sexual problems: Perceived effects on men's and women's sexual partners. J Sex Res 2017;55:226-235.

54. Carvalheira A, Træen B, Štulhofer A. Correlates of men's sexual interest: A cross-cultural study. J Sex Med 2014;11:154-164.

55. Baćak V, Štulhofer A. Masturbation among sexually active young women in Croatia: Associations with religiosity and pornography use. Int J Sex Health 2011;23:248-257.

56. Štulhofer A, Šoh D, Jelaska N, et al. Religiosity and sexual risk behavior among Croatian college students, 1998-2008. J Sex Res 2011;48:360-371.

57. Lewin B, Fugl-Meyer K, Helmius G, et al. Sex i Sverige; Om sexuallivet i Sverige 1996. Stockholm: Folkehälsoinstitutet; 1998 [in Swedish].

58. Hubert M, Bajos N, Sandfort T. Sexual behaviour and HIV/ AIDS in Europe: Comparisons of national surveys. London: UCL Press; 1998. 
59. Avlund K, Osler M, Mortensen EL, et al. Copenhagen Aging and Midlife Biobank (CAMB). J Aging Health 2014;26:5-20.

60. Søgaard $H J$, Bech P. Psychometric analysis of Common Mental Disorders-Screening Questionnaire (CMD-SQ) in long-term sickness absence. Scand J Public Health 2009; 37:855-863.

61. American Psychiatric Association. Diagnostic and statistical manual of mental disorders (DSM-5). 5th ed. Washington, DC: American Psychiatric Association; 2013.

62. Ware J, Kosinski MA, Keller SD. SF-12: How to score the SF-12 physical and mental health summary scales. 2nd ed. Boston, MA: The Health Institute, New England Medical Center; 1995.

63. National Survey of Sexual Attitudes and Lifestyles. The National Survey of Sexual Attitudes and Lifestyles questionnaire computer question listings revised for Natsal 3 [pdf file]. Available at: http://www.natsal.ac.uk/media/2078/bl-capiand-casi-questionnaire.pdf.; Accessed: April 8, 2019.

64. Schafer J, Graham J. Missing data: Our view of the state of the art. Psychol Methods 2002;7:147-177.

65. Carvalho J, Vieira A, Nobre P. Structures of male sexual functioning. J Sex Med 2011;8:2501-2511.

66. Christensen B, Grønbæk S, Osler M, et al. Sexual dysfunctions and difficulties in Denmark: Prevalence and associated sociodemographic factors. Arch Sex Behav 2011;40:121-132.

67. Lee D, Nazroo J, Pendleton N. Erectile dysfunction and phosphodiesterase type 5 inhibitor use: Associations with sexual activities, function and satisfaction in a population sample of older men. Int J Impot Res 2015;27:146-151.
68. Bell S, Reissing ED, Henry LA, et al. Sexual activity after 60: A systematic review of associated factors. Sex Med Rev 2017; 5:52-80.

69. Fisher L, Anderson CO, Chapagain M, et al. Sex, romance, and relationships: AARP survey of midlife and older adults. Washington, DC: AARP Research; 2010.

70. Fileborn B, Hinchliff S, Lyons A, et al. The importance of sex and the meaning of sex and sexual pleasure for men aged 60 and older who engage in heterosexual relationships: Findings from a qualitative interview study. Arch Sex Behav 2017; 46:2097-2110.

71. Hinchliff S, Gott M. Seeking medical help for sexual concerns in mid- and later life: A review of the literature. J Sex Res 2011;48:106-117.

72. Mellor RM, Greenfield SM, Dowswell G, et al. Health care professionals' views on discussing sexual well-being with patients who have had a stroke: A qualitative study. PLoS One 2013;8:e78802.

73. Jannini EA, Sternbach N, Limoncin E, et al. Health-related characteristics and unmet needs of men with erectile dysfunction: A survey in five European countries. J Sex Med 2014;11:40-50.

74. McDonaugh LK, Nielsen EJ, McDermott DT, et al. "I want to feel like a full man": Conceptualizing gay, bisexual, and heterosexual men's sexual difficulties. J Sex Res 2017; 55:783-801.

75. Latini DM, Penson DF, Wallace KL, et al. Clinical and psychosocial characteristics of men with erectile dysfunction: Baseline data from ExCEED. J Sex Med 2006;3:1059-1067. 